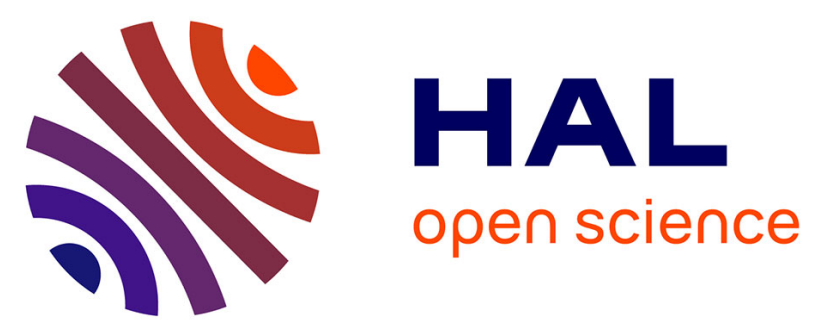

\title{
Ellagitannins Inhibit the Exsheathment of Haemonchus contortus and Trichostrongylus colubriformis Larvae: The Efficiency Increases Together with the Molecular Size
}

\author{
Maarit Karonen, Jeffrey Ahern, Lucie Legroux, Jussi Suvanto, Marica \\ Engström, Jari Sinkkonen, Juha-Pekka Salminen, Hervé Hoste
}

\section{To cite this version:}

Maarit Karonen, Jeffrey Ahern, Lucie Legroux, Jussi Suvanto, Marica Engström, et al.. Ellagitannins Inhibit the Exsheathment of Haemonchus contortus and Trichostrongylus colubriformis Larvae: The Efficiency Increases Together with the Molecular Size. Journal of Agricultural and Food Chemistry, 2020, 68 (14), pp.4176-4186. 10.1021/acs.jafc.9b06774 . hal-03206957

\section{HAL Id: hal-03206957 https://hal.inrae.fr/hal-03206957}

Submitted on 23 Apr 2021

HAL is a multi-disciplinary open access archive for the deposit and dissemination of scientific research documents, whether they are published or not. The documents may come from teaching and research institutions in France or abroad, or from public or private research centers.
L'archive ouverte pluridisciplinaire HAL, est destinée au dépôt et à la diffusion de documents scientifiques de niveau recherche, publiés ou non, émanant des établissements d'enseignement et de recherche français ou étrangers, des laboratoires publics ou privés. 


\title{
Ellagitannins Inhibit the Exsheathment of Haemonchus contortus and Trichostrongylus colubriformis Larvae: The Efficiency Increases Together with the Molecular Size
}

\author{
Maarit Karonen,* Jeffrey R. Ahern, Lucie Legroux, Jussi Suvanto, Marica T. Engström, Jari Sinkkonen, \\ Juha-Pekka Salminen, and Hervé Hoste
}

Cite This: J. Agric. Food Chem. 2020, 68, 4176-4186

Read Online

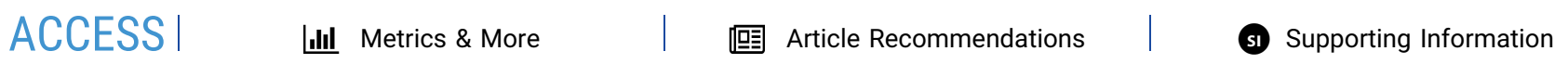

ABSTRACT: Worldwide, parasitic gastrointestinal nematodes continue to threaten animal health, welfare, and production in outdoor breeding systems of small ruminants. For more than 50 years, the control of these parasitic worms has relied on the use of commercial synthetic anthelmintics. However, anthelmintic resistance in worm populations is nowadays widespread and requires novel solutions. The use of tannin-rich plants has been suggested as an alternative to synthetic anthelmintics to control gastrointestinal nematodes. The majority of previous studies have focused on the activity of proanthocyanidins (syn condensed tannins), and less is known about ellagitannins. In this study, the effects of 30 structurally unique ellagitannins on the exsheathment of third-stage infective larvae were examined on Haemonchus contortus and Trichostrongylus colubriformis by the in vitro larval exsheathment inhibition assay. Ellagitannins were found to be promising natural anthelmintics as they showed direct inhibition on larval exsheathment for both nematode species. In general, ellagitannins were more efficient at inhibiting the exsheathment of $H$. contortus larvae than those of $T$. colubriformis. The efficiency of inhibition increased as the degree of oligomerization or the molecular weight of the ellagitannin increased. Otherwise, we found no other structural features of ellagitannins that significantly affected the anthelmintic activity on the third-stage infective larvae. The effective concentrations were physiologically relevant and should be achievable in the gastrointestinal tract also in in vivo conditions.

KEYWORDS: anthelmintic, parasitic nematodes, polyphenols, structure-activity relationship, tannins, third-stage larvae

\section{INTRODUCTION}

Parasitic nematodes of the gastrointestinal tract remain a major threat to small ruminant health, welfare, and production. ${ }^{1,2}$ Broad-spectrum anthelmintic drugs with varying chemical structures have been used for more than 50 years for eliminating worms from hosts. However, due to repeated use, the resistance to these anthelmintic drugs has now been recognized worldwide. At the moment, resistance to anthelmintics has become a major problem in veterinary medicine. $^{3-5}$ In small ruminants, resistance has evolved to all of the major families of broad-spectrum anthelmintics, such as benzimidazoles, levamisole, and macrocyclic lactones (avermectins and milbemycins), seriously hindering efficacy. In addition, reports on multiresistant isolates are increasing. ${ }^{6}$ In cattle and horses, the situation is not yet so severe, but they also have nematodes resistant to multiple anthelmintic classes. ${ }^{3}$ Therefore, alternative, sustainable options are urgently needed to ensure sheep and goat welfare and health. There is also a clear need to address the increasing societal demands of consumers to reduce the use of synthetic chemicals in various farming systems. This is illustrated by the demand and development of organic livestock farming systems and products, which do not use synthetic anthelmintics but require novel alternative options to reduce worm infection.

One possible approach is the use of bioactive plants and their secondary metabolites. For nearly 20 years, many studies have focused on forages and fodders containing condensed tannins, and in vivo and in vitro results suggest that such tannin-rich plants represent an alternative solution to commercial anthelmintics. ${ }^{7-12}$ Using naturally tannin-rich plants is an attractive possibility to provide affordable, sustainable, and organic control of parasitic nematodes. These plants could act either through a direct mode of action or indirectly by increasing the host resistance. ${ }^{13}$ It has been postulated that tannins can interfere with nematode biology due to their ability to bind to parasite proteins. ${ }^{11,14}$ This can inhibit or delay some key steps in the nematode life cycle, such as the exsheathment of infective third-stage larvae or the ability of infective stages to penetrate into the digestive mucosae. However, variable anthelmintic activities have been reported depending on the nature of the tannins, the host, the parasite species, and/or the stage. 9,12

Plant tannins, i.e., proanthocyanidins (syn condensed tannins), hydrolyzable tannins, and phlorotannins, are a unique and large group of plant secondary metabolites with

Received: October 28, 2019

Revised: March 17, 2020

Accepted: March 17, 2020

Published: March 17, 2020 
diverse structures. They have the ability to form complexes with and precipitate proteins. Proanthocyanidins are oligomers and polymers of flavan-3-ols, and they are the most common and studied group of tannins. Hydrolyzable tannins are structurally the most diverse group of tannins and can be divided into three subclasses: simple gallic acid derivatives, gallotannins, and ellagitannins (ETs). ETs can be further divided into six subgroups: hexahydroxydiphenoyl (HHDP) esters, dehydroHHDP esters and their modifications, nonahydroxytriphenoyl (NHTP) esters, flavanoellagitannins, and oligomers with varying degrees of oligomerization and types of bonds between the monomers. ${ }^{15}$ This variety of structural features manifests in great diversity of ETs, with over 1000 unique ET structures described so far. ${ }^{16}$

Previously, great variability has been observed in studies about the anthelmintic effects of different tannin mixtures in vitro and in vivo. ${ }^{11,12}$ These studies have included the effects of different tannins on the various parasitic stages of nematodes exploring the relationships between the tannin structure and the bioactivity, namely, the anthelmintic effects ${ }^{11,12,14,17,18}$ (and references therein), but have been mostly conducted using proanthocyanidin mixtures. ${ }^{19-23}$ At the moment, the picture is complex and needs further research as the chemical basis for these effects is not known, much due to the fact that the proanthocyanidin mixtures used in plant-ruminant studies have not been chemically fully characterized. So far, ETs have not been extensively studied for their possible anthelmintic effects. One study on the anthelmintic effects of ETs showed that the ET-containing chestnut extract can totally inhibit the exsheathment of Trichostrongylus colubriformis larvae. ${ }^{14}$ In addition, our previous study showed that hydrolyzable tannins can affect the egg hatching and the motility of L1- and L2-stage larvae of Haemonchus contortus. ${ }^{24}$ These results indicated a clear relationship between the structure of the hydrolyzable tannin and the anthelmintic activity. The anthelmintic activity was affected by the size and flexibility of hydrolyzable tannins as well as the types and numbers of functional groups of hydrolyzable tannins and the types of linkages between monomeric hydrolyzable tannin units. ${ }^{24}$

In general, more detailed studies are clearly needed to understand which plant ETs could be utilized as anthelmintic agents against gastrointestinal nematodes. Therefore, we wanted to further study the possibility of using ETs as alternatives for anthelmintic drugs against gastrointestinal nematodes of small ruminants. In this study, two nematode species were used as parasitic models: the abomasal species $H$. contortus and the intestinal species T. colubriformis. The main aim was to evaluate the anthelmintic effects of 30 individual ETs by the larval exsheathment inhibition assay (LEIA) to find out how a structurally diverse array of ETs differs at inhibiting the third-stage infective larvae (L3) of parasitic nematodes of ruminants. The exsheathment of L3 is a crucial step in the life cycle since it represents the transition from the free-living to the parasitic stage.

\section{MATERIALS AND METHODS}

Plant Materials. The following plant materials were collected during the summer of 2011 from southwestern Finland: willowherb flowers (Epilobium angustifolium), silverweed leaves (Potentilla anserina), herb bennet leaves (Geum urbanum), English oak acorns (Quercus robur), purple loosestrife leaves and flowers (Lythrum salicaria), meadowsweet flowers (Filipendula ulmaria), raspberry leaves (Rubus idaeus), and wood cranesbill leaves (Geranium sylvaticum). The plant materials were collected directly in $1 \mathrm{~L}$ glass bottles; 10 bottles were collected for each plant species. ${ }^{24-26}$ After that, the bottles were immediately filled with acetone, transferred to the laboratory, and left to macerate in a cold room $\left(+4{ }^{\circ} \mathrm{C}\right)$ prior to the isolation of ETs. The material of sea buckthorn (Hippophäe rhamnoides) was the same as previously used. ${ }^{27}$ These plants were selected because they represented potential resources to isolate a range of pure ETs with different structures.

Isolation and Purification of Ellagitannins. The extraction of phenolic compounds and the isolation of ETs followed mainly our previous methods. ${ }^{24-26,28-32}$ However, some modifications were made. In brief, the crude plant extracts were obtained directly from the bottles where the collected plant materials were left to macerate for several weeks. The extracts were combined species by species and concentrated to $300-500 \mathrm{~mL}$ of the water phase. The concentrated water phases of crude extracts were fractionated twice with Sephadex LH-20 chromatography. ${ }^{25}$ First, a rough fractionation of the crude extract with the Sephadex LH-20 material was performed in a beaker, and then, a careful fractionation was performed for a selected fraction by Sephadex LH-20 column chromatography. The rough fractionation was started by mixing the water phase of the crude extract with the swollen Sephadex LH-20 material (in water), and then, separations were performed batchwise using water, 50\% aqueous methanol, methanol, $80 \%$ aqueous acetone, and acetone as eluents. In column chromatography on Sephadex LH-20, the glass column $(300 \mathrm{~mm} \times$ $50 \mathrm{~mm}$ ) was manually filled with swollen gel (height approximately $230 \mathrm{~mm}$ ), and different eluents, such as water, aqueous methanol, and aqueous acetone, were used depending on the ET to be isolated. Obtained fractions were concentrated to the water phase and freezedried. All steps were followed by ultraperformance liquid chromatography (UPLC) - diode array detector-mass spectrometry (DADMS) with detection at $190-450 \mathrm{~nm} \cdot{ }^{25,26}$ The isolation of ETs from the Sephadex fractions was performed by preparative high-performance liquid chromatography (HPLC) as previously but with detection at $190-450 \mathrm{~nm}^{25,26}$ Different gradients were used for different ETs. The final purification of ETs was performed by semipreparative HPLC with the same HPLC-DAD system as before with detection at 190-450 nm. ${ }^{25,26}$ Different gradients were used for different ETs; e.g., a typical gradient for acyclic ETs was as follows: $0-5 \mathrm{~min}, 2 \% \mathrm{~B}$ (acetonitrile) in A (0.1\% formic acid); $5-51 \mathrm{~min}, 2-32 \% \mathrm{~B}$ in A; $51-$ $55 \mathrm{~min}, 32-70 \% \mathrm{~B}$ in $\mathrm{A}$; column wash and stabilization, with detection at $190-450 \mathrm{~nm}$. All steps in the preparative and semipreparative purifications were followed by UPLC-DAD-MS with detection at $190-450 \mathrm{~nm} .^{25,26}$ Obtained fractions and pure ETs were concentrated to the water phase and freeze-dried.

Structural Characterization of ETs. All fractions obtained by Sephadex LH-20 fractionation, by preparative HPLC, or by semipreparative HPLC and the purified ETs were analyzed by UPLC-DAD-MS as previously but with detection at 190-450 $\mathrm{nm} .{ }^{25,26}$ Most of the ellagitannins had been previously characterized by chromatographic, NMR spectroscopic, and mass spectrometric methods and the corresponding data published..$^{25-27,29,31-46}$ The identification of those ellagitannins was performed by UPLCDAD-MS by comparing the information of retention times, UV spectra, and molecular masses and characteristic electrospray ionization (ESI)-MS fragmentations with the existing knowledge. The NMR experiments were performed only for the ETs that we had not characterized earlier with a Bruker Avance 500 NMR spectrometer operating at $500.13 \mathrm{MHz}$ for ${ }^{1} \mathrm{H}$ NMR and 125.77 $\mathrm{MHz}$ for ${ }^{13} \mathrm{C}$ NMR or with an Avance III 600 NMR spectrometer operating at $600.16 \mathrm{MHz}$ for ${ }^{1} \mathrm{H}$ NMR and $150.93 \mathrm{MHz}$ for ${ }^{13} \mathrm{C}$ NMR. Spectra were recorded at $25{ }^{\circ} \mathrm{C}$ using acetone- $d_{6}$ or methanol$d_{4}$ as a solvent. The measurements included ${ }^{1} \mathrm{H}$ and ${ }^{13} \mathrm{C}$ NMR spectra, in addition to several two-dimensional (2D) spectra such as doublequantum filtered correlation spectroscopy (DQF-COSY), $\mathrm{CH}_{2}$-edited heteronuclear single quantum coherence (HSQC), heteronuclear multiple bond correlation (HMBC), and one-dimensional total correlation spectroscopy (1D-TOCSY).

The structures of individual ET monomers are presented in Figure 1 and dimeric and trimeric ET oligomers in Figure 2. The structures 


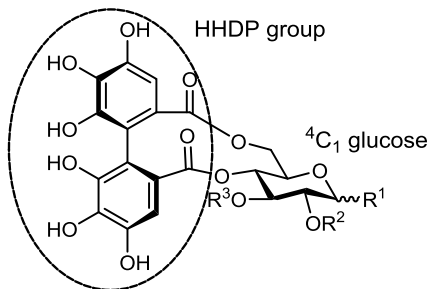

1 Tellimagrandin $\mathrm{IR}^{1}=\mathrm{OH}, \mathrm{R}^{2}=\mathrm{R}^{3}=\mathrm{G}$ 18 Tellimagrandin II $\mathrm{R}^{1}=\beta$-OG, $\mathrm{R}^{2}=\mathrm{R}^{3}=\mathrm{G}$ 20 Pedunculagin $\mathrm{R}^{1}=\mathrm{OH}, \mathrm{R}^{2} \sim \mathrm{R}^{3}=(S)$-HHDP 28 Casuarictin $\mathrm{R}^{1}=\beta$-OG, $\mathrm{R}^{2} \sim \mathrm{R}^{3}=(S)$-HHDP

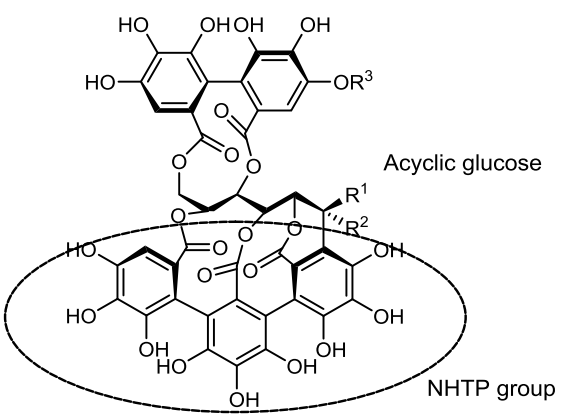

11 Castalagin $\mathrm{R}^{1}=\mathrm{R}^{3}=\mathrm{H}, \mathrm{R}^{2}=\mathrm{OH}$ 12 Vescalagin $\mathrm{R}^{1}=\mathrm{OH}, \mathrm{R}^{2}=\mathrm{R}^{3}=\mathrm{H}$ 16 Vescavaloninic acid $\mathrm{R}^{1}=\mathrm{OH}, \mathrm{R}^{2}=\mathrm{H}, \mathrm{R}^{3}=\mathrm{A}$ 17 Castavaloninic acid $\mathrm{R}^{1}=\mathrm{H}, \mathrm{R}^{2}=\mathrm{OH}, \mathrm{R}^{3}=\mathrm{A}$

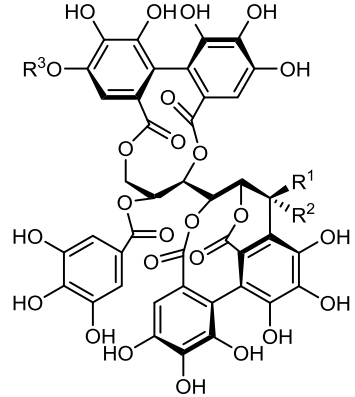

26 Stachyurin $\mathrm{R}^{1}=\mathrm{OH}, \mathrm{R}^{2}=\mathrm{R}^{3}=\mathrm{H}$ 27 Casuarinin $\mathrm{R}^{1}=\mathrm{R}^{3}=\mathrm{H}, \mathrm{R}^{2}=\mathrm{OH}$ 29 Hippophaenin $\mathrm{CR}^{1}=\mathrm{OH}, \mathrm{R}^{2}=\mathrm{H}, \mathrm{R}^{3}=\mathrm{A}$ 30 Hippophaenin $B \mathrm{R}^{1}=\mathrm{H}, \mathrm{R}^{2}=\mathrm{OH}, \mathrm{R}^{3}=\mathrm{A}$
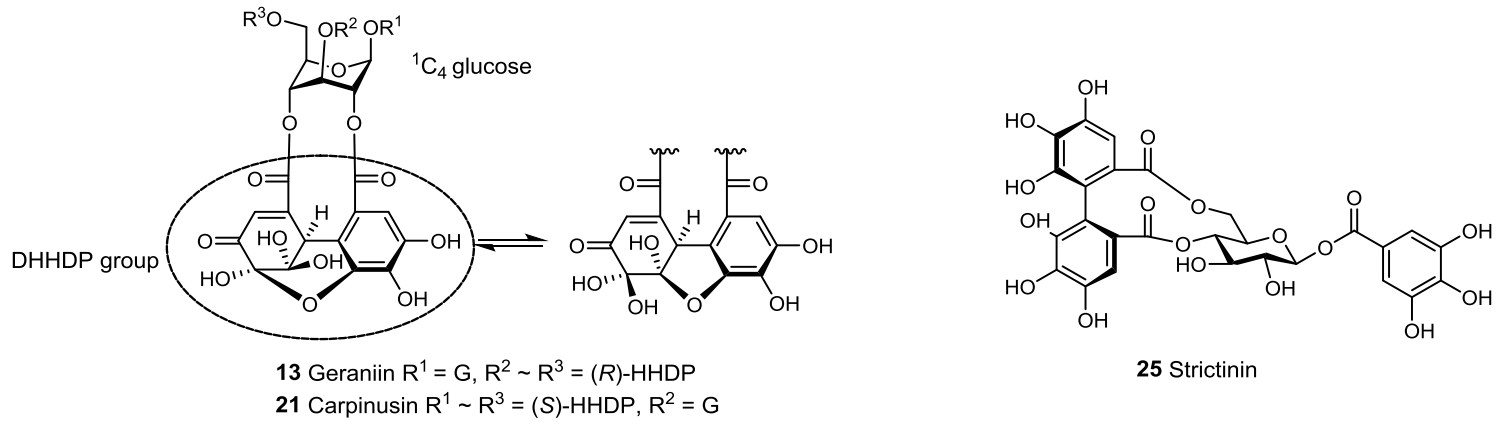

Figure 1. Structures of monomeric ellagitannins studied. The configuration of the NHTP group is revised according to Matsuo et al. ${ }^{47} \mathrm{~A}$, gallic acid; DHHDP, dehydrohexahydroxydiphenoyl group; G, galloyl group; HHDP, hexahydroxydiphenoyl group; and NHTP, nonahydroxytriphenoyl group.

of tetrameric (4), pentameric (5), hexameric (6), heptameric (7), and longer ET oligomers (8) are formed from trimeric oenothein A (3) when additional tellimagrandin I (1, Figure 1$)$ monomers are attached to the ellagitannin chain by one DOG-type linkage. ${ }^{32}$ The plant materials used in the isolation of ETs, the purity of ETs by UPLC at $280 \mathrm{~nm}$, and the data of confirmation of their identification by ESIMS are all shown in Table 1. The stereochemistries of castalagin and vescalagin were recently reinvestigated by computational methods, and the nonahydroxytriphenoyl group (NHTP) was found to exist in the $(\mathrm{S}, \mathrm{R})$ configuration. ${ }^{47}$ Therefore, it is feasible that the NHTP group of vescavaloninic and castavaloninic acids is also in the $(S, R)$ configuration. The structures of tellimagrandin II (18), roshenin C (19), salicarinin A (24), and strictinin (25) were confirmed by NMR spectroscopy, and the corresponding data are presented in the Supporting Information (Figures S1, S2, and Tables S1-S5). The NMR data of vescalagin (12) was used in the characterization of salicarinin A (24). In addition, NMR was used for hippophaenins, which were confirmed to be hippophaenin B ( $\alpha$ anomer, 30 in Figure $1)$ and hippophaenin $C$ ( $\beta$ anomer, 29 in Figure 1$)$ based on our previous characterization. ${ }^{46}$

In short, the identification of the analyzed ellagitannins started from the core sugar signals. The $\beta$-glucose moiety was easily recognized based on rather large coupling constants between protons $\mathrm{H} 1$ and $\mathrm{H} 2$ (approx $8.2 \mathrm{~Hz}$ ) and large coupling between $\mathrm{H} 2-\mathrm{H} 3$, $\mathrm{H} 3-\mathrm{H} 4$, and $\mathrm{H} 4-\mathrm{H} 5$ (approx $9.8 \mathrm{~Hz}$ ). These were found for strictinin, tellimagrandin II, and other sugar units of roshenin C. However, another sugar moiety of roshenin $\mathrm{C}$ had coupling constant $\mathrm{H} 1-\mathrm{H} 2$ as $4.1 \mathrm{~Hz}$, which is a clear indication of $\alpha$-anomeric glucose. For vescalagin and salicarinin A, the sugar signals had many small couplings and no carbon signal around $90 \mathrm{ppm}$. Therefore, they were identified as $\mathrm{C}$-glycosidic open chain sugars. The configuration between $\alpha$ - and $\beta$-anomers (position 1) can be deduced from the coupling constant, where it is approx. $2 \mathrm{~Hz}$ in $\beta$-anomers and approx. $5 \mathrm{~Hz}$ in $\alpha$-anomers. Therefore, these compounds were found to have only $\beta$-anomers. After the core sugars were identified, the phenolic parts could be linked by $\mathrm{HMBC}$ correlations from the sugar proton to corresponding carbonyl carbons. Thereafter, HMBC correlations from carbonyl carbons to aromatic protons could be seen at galloyl and HHDP groups. Depending on the overlapping of carbon signals, the full assignment of signals could proceed. In another case, for example in the case of the NHTP moiety, lack of protons inhibited having information from long-range correlations.

Larval Exsheathment Inhibition Assay (LEIA). The assay was performed as previously described. ${ }^{14}$ Briefly, ensheathed third-stage larvae (L3) of H. contortus (ca. 1000) or of T. colubriformis from the same 2-month-old batch were incubated for $3 \mathrm{~h}$ at $20{ }^{\circ} \mathrm{C}$ separately with each of the 30 ETs. ETs were diluted in phosphate-buffered solution (PBS; $\mathrm{pH} 7.2$ ) to avoid any interference due to $\mathrm{pH}$ change. In general, four different concentrations were used for ETs: $0 \mathrm{mM}$ (negative control), 6.25, 25, 100, and $400 \mu \mathrm{M}$. If needed, an additional concentration of $200 \mu \mathrm{M}$ was used. After incubation, the larvae were washed and centrifuged $(1000 \mathrm{rpm})$ three times in PBS $(\mathrm{pH}$ 7.2). Next, the larvae were submitted to an artificial process of exsheathment by contact with a solution of sodium hypochlorite $(2 \%$, $\mathrm{w} / \mathrm{v})$ and sodium chloride (16.5\%, w/v) diluted in 1-300 in PBS ( $\mathrm{pH}$ 7.2) for both nematode species. The kinetics of larval exsheathment between the different experimental treatments was monitored by microscopic observation (200x). The percentages of exsheathed larvae were identified at 20, 40, and 60 min intervals. Four replicates were run for each ET to examine the changes in the proportion of exsheathed larvae with time.

Statistical Analyses of the Results. All statistical analyses were performed with SAS 9.4 (SAS Institute, Cary NC). Responses of $H$. contortus and T. colubriformis were examined in separate, but identical, statistical models. The response variable was the difference in response from the control, which was calculated with the following formula (where trt refers to treatment): 

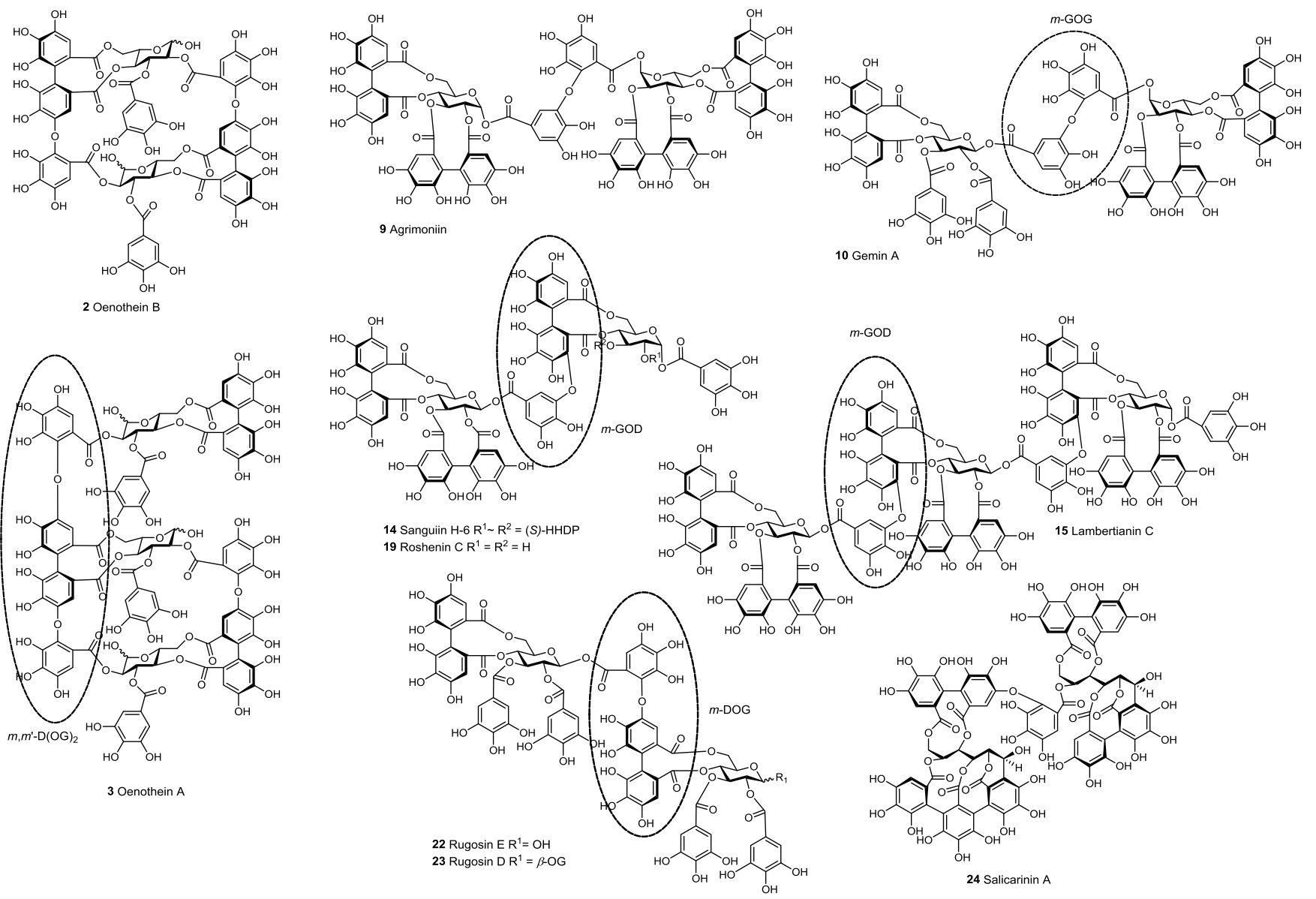

Gemin A
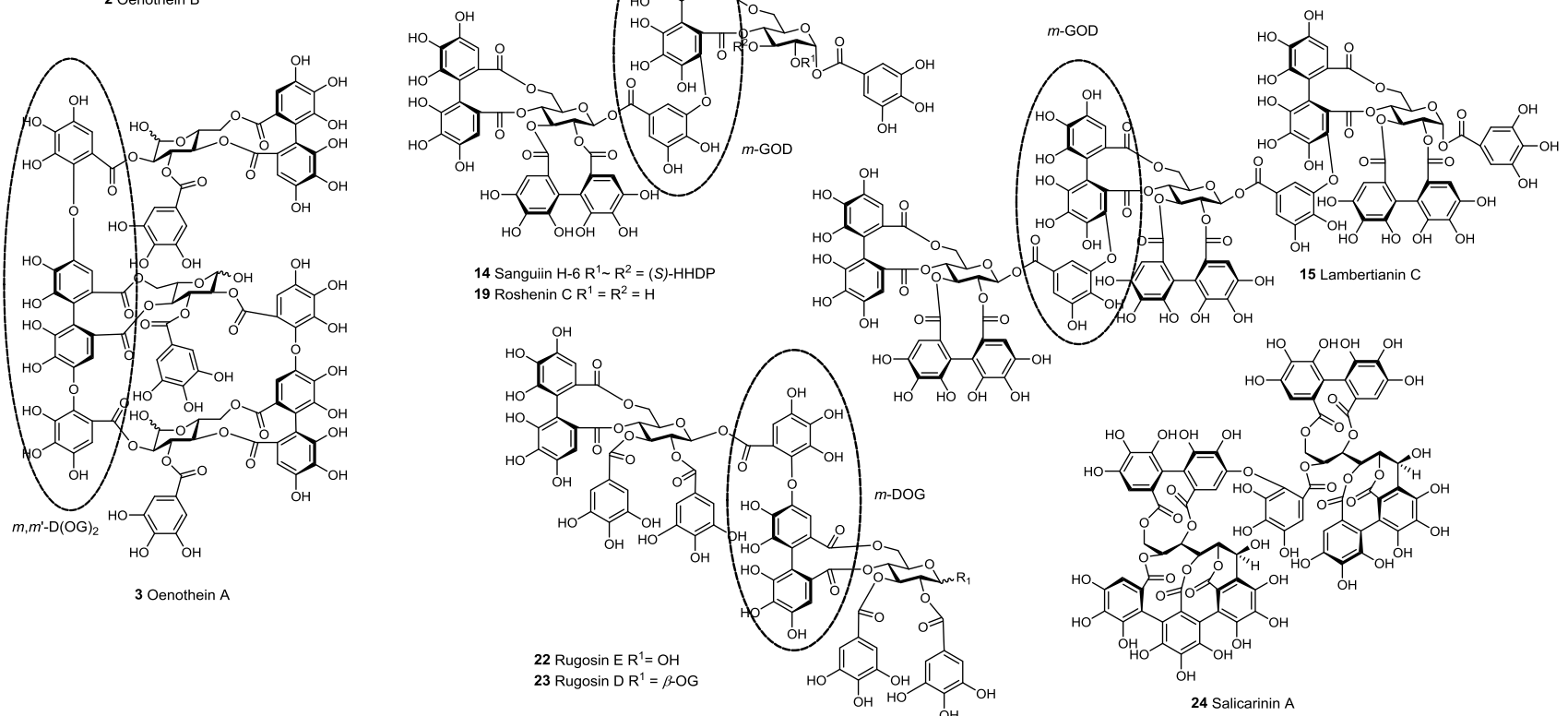

Figure 2. Structures of oligomeric ellagitannins studied. Tetrameric (4), pentameric (5), hexameric (6), heptameric (7), and longer oligomers (8) are formed from trimeric oenothein A (3) when additional tellimagrandin I (1, Figure 1) monomers are attached to the ellagitannin chain by one DOG-type linkage. ${ }^{32}$ The monomers are linked to each other via $m$-DOG (valoneoyl), $m$-GOG (dihydrogalloyl), $m$-GOD (sanguisorboyl), and $\mathrm{D}(\mathrm{OG})_{2}$ linkages. The configuration of the nonahydroxytriphenoyl group in salicarinin A (24) is revised according to Matsuo et al. ${ }^{47} \mathrm{HHDP}$, hexahydroxydiphenoyl group.

$$
\begin{aligned}
& \text { difference from control } \\
& =\frac{\sum \text { exsheathed larvae (control) }}{\sum \text { total larvae }(\text { control })}-\frac{\sum \text { exsheathed larvae }(\text { trt })}{\sum \text { total larvae }(\text { trt })}
\end{aligned}
$$

This response accounted for variation between controls in separate trials. Data were analyzed with a repeated-measures analysis of covariance (ANCOVA) model in Proc MIXED. Compound identity and time $(20,40$, and $60 \mathrm{~min})$ were treated as categorical variables, while concentration was treated as a continuous variable. The model consisted of the main effects of ET compound identity, time, concentration, and the interactive effect of compound by concentration. Time was included as a repeated factor. The differences in response between compounds were tested by comparing least-squares mean values. To account for multiple comparisons, the BenjaminiHochberg false discovery rate procedure in Proc MULTEST was implemented to adjust $p$-values. ${ }^{50}$

\section{RESULTS}

Larval Exsheathment in Controls. The control measurements were performed with PBS, which was used to avoid the effects caused by a change in $\mathrm{pH}$. The aim of the control measurements was to obtain an exsheathment curve as a function of time with an ending point with $100 \%$ exsheathment at $60 \mathrm{~min}$. For $H$. contortus, the larvae exsheathment usually began $20 \mathrm{~min}$ after the addition of sodium hypochlorite solution (Figure S3A,B in the Supporting Information), as for T. colubriformis (Figure S3C in the Supporting Information).
After 40 min, nearly $100 \%$ of the larvae were exsheathed in the control solution.

Effect of ETs on Larval Exsheathment. The in vitro tests were performed using pure ETs to understand the relationship between the ET structure and the activity observed. A diverse set of 30 ETs was used: these ETs represented the biosynthetic pathway and diversity of ET structures found in plants, since different plant species produce very different ETs. ${ }^{33}$ The ETs studied included monomeric ETs, such as simple HHDP esters having a ${ }^{4} \mathrm{C}_{1}$-glucopyranose configuration (e.g., tellimagrandin I (1) and strictinin (25) in Figure 1), DHHDP esters with a ${ }^{1} \mathrm{C}_{4}$-glucopyranose configuration (e.g., geraniin (13) and carpinusin (21) in Figure 1), and C-glycosidic ETs with an acyclic glucose core (castalagin (11) and vescalagin (12) in Figure 1). Also, dimeric ETs with a linkage via a metadehydrodigalloyl ( $m$-GOG) group (e.g., agrimoniin (9) and gemin A (10) in Figure 2), via a sanguisorboyl ( $m$-GOD) group (e.g., sanguiin H-6 (14) and roshenin C (19) in Figure 2 ), or via a valoneoyl ( $m$-DOG) group (e.g., rugosin E (22) and rugosin D (23) in Figure 2) were used, in addition to a set of oligomeric ETs from the dimer up to the heptamer and a mixture of oligo- to polymers (Figure 2).

All ETs more or less inhibited the exsheathment of both $H$. contortus and $T$. colubriformis larvae in a wide range of differences when compared to the control. These differences 
Table 1. Individual Ellagitannins Tested, Plant Materials Used for Their Isolation, Their Purity Obtained by UPLC at $280 \mathrm{~nm}$, and Confirmation of Their Identification by ESI-MS

\begin{tabular}{|c|c|c|c|c|c|}
\hline no. & ellagitannin & $\begin{array}{l}\text { plant material used in } \\
\text { the isolation }\end{array}$ & $\begin{array}{c}\text { purity } \\
(\%)\end{array}$ & ESI-MS identification $(\mathrm{m} / z)$ & literature \\
\hline 1 & $\begin{array}{l}\text { tellimagrandin I } \\
(\mathrm{TI})\end{array}$ & $\begin{array}{l}\text { meadowsweet } \\
\text { inflorescence }\end{array}$ & 97.5 & $785[\mathrm{M}-\mathrm{H}]^{-}$ & 29 and 35 \\
\hline 2 & $\begin{array}{l}\text { oenothein } \mathrm{B} \\
\text { (dimeric } \mathrm{TI})\end{array}$ & $\begin{array}{l}\text { willowherb } \\
\text { inflorescence }\end{array}$ & 98.7 & $783[\mathrm{M}-2 \mathrm{H}]^{2-}$ & 31 and 35 \\
\hline 3 & $\begin{array}{l}\text { oenothein A } \\
\text { (trimeric TI) }\end{array}$ & $\begin{array}{l}\text { willowherb } \\
\text { inflorescence }\end{array}$ & 99.3 & $1175[\mathrm{M}-2 \mathrm{H}]^{2-}$ & 32 and 34 \\
\hline 4 & tetrameric TI & $\begin{array}{l}\text { willowherb } \\
\text { inflorescence }\end{array}$ & 96.8 & $1045[\mathrm{M}-3 \mathrm{H}]^{3-}, 1567[\mathrm{M}-2 \mathrm{H}]^{2-}$ & 32 and 34 \\
\hline 5 & pentameric TI & $\begin{array}{l}\text { willowherb } \\
\text { inflorescence }\end{array}$ & 96.3 & $1307[\mathrm{M}-3 \mathrm{H}]^{3-}, 1960[\mathrm{M}-2 \mathrm{H}]^{2-}$ & 32 and 34 \\
\hline 6 & hexameric TI & $\begin{array}{l}\text { willowherb } \\
\text { inflorescence }\end{array}$ & 89.9 & $1568[\mathrm{M}-3 \mathrm{H}]^{3-}$ & 32 and 34 \\
\hline 7 & heptameric TI & $\begin{array}{l}\text { willowherb } \\
\text { inflorescence }\end{array}$ & 90.4 & $1829[\mathrm{M}-3 \mathrm{H}]^{3-}$ & 32 and 34 \\
\hline 8 & $\begin{array}{l}\text { oligomeric and } \\
\text { polymeric TIs }\end{array}$ & $\begin{array}{l}\text { willowherb } \\
\text { inflorescence }\end{array}$ & 99.0 & $\begin{array}{l}1568[\mathrm{M}-4 \mathrm{H}]^{4-} \text { (octamer), } 1764[\mathrm{M}-4 \mathrm{H}]^{4-} \text { (nonamer), } 1961[\mathrm{M}-4 \mathrm{H}]^{4-} \\
(\text { decamer) }\end{array}$ & 15 and 32 \\
\hline 9 & agrimoniin & silverweed leaves & 97.7 & $934[\mathrm{M}-2 \mathrm{H}]^{2-}, 301[\text { ellagic acid }-\mathrm{H}]^{-}$ & $\begin{array}{l}31,35 \\
\text { and } 48\end{array}$ \\
\hline 10 & gemin $\mathrm{A}$ & herb bennet leaves & 98.2 & $935[\mathrm{M}-2 \mathrm{H}]^{2-}, 301[\text { ellagic acid }-\mathrm{H}]^{-}$ & 31 and 49 \\
\hline 11 & castalagin & $\begin{array}{l}\text { purple loosestrife } \\
\text { flowers and leaves }\end{array}$ & 99.6 & $933[\mathrm{M}-\mathrm{H}]^{-}, 466[\mathrm{M}-2 \mathrm{H}]^{2-}, 301[\text { ellagic acid }-\mathrm{H}]^{-}$ & $\begin{array}{l}35,37 \\
\text { and } 38\end{array}$ \\
\hline 12 & vescalagin & $\begin{array}{l}\text { purple loosestrife } \\
\text { flowers and leaves }\end{array}$ & 94.1 & $\begin{array}{l}933[\mathrm{M}-\mathrm{H}]^{-}, 915\left[\mathrm{M}-\mathrm{H}_{2} \mathrm{O}-\mathrm{H}\right]^{-}, 466[\mathrm{M}-2 \mathrm{H}]^{2-}, 457\left[\mathrm{M}-\mathrm{H}_{2} \mathrm{O}-2 \mathrm{H}\right]^{2-} \\
301[\text { ellagic acid }-\mathrm{H}]^{-}\end{array}$ & $\begin{array}{l}35,37 \\
\text { and } 38\end{array}$ \\
\hline 13 & geraniin & wood cranesbill leaves & 98.3 & $951[\mathrm{M}-\mathrm{H}]^{-}, 933\left[\mathrm{M}-\mathrm{H}_{2} \mathrm{O}-\mathrm{H}\right]^{-}, 301[\text { ellagic acid }-\mathrm{H}]^{-}$ & 39 \\
\hline 14 & sanguiin $\mathrm{H}-6$ & raspberry leaves & 97.6 & $934[\mathrm{M}-2 \mathrm{H}]^{2-}, 301[\text { ellagic acid }-\mathrm{H}]^{-}$ & 31 and 40 \\
\hline 15 & lambertianin $\mathrm{C}$ & raspberry leaves & 95.6 & $934[\mathrm{M}-3 \mathrm{H}]^{3-}, 301[\text { ellagic acid }-\mathrm{H}]^{-}$ & 31 and 40 \\
\hline 16 & vescavaloninic acid & english oak acorns & 95.6 & $\begin{array}{l}1101[\mathrm{M}-\mathrm{H}]^{-}, 1083\left[\mathrm{M}-\mathrm{H}_{2} \mathrm{O}-\mathrm{H}\right]^{-}, 528[\mathrm{M}-\mathrm{COOH}-\mathrm{H}]^{2-}, 519 \\
\quad\left[\mathrm{M}-\mathrm{H}_{2} \mathrm{O}-\mathrm{COOH}-\mathrm{H}\right]^{2-}, 301[\text { ellagic acid }-\mathrm{H}]^{-}\end{array}$ & 41 and 42 \\
\hline 17 & castavaloninic acid & english oak acorns & 99.6 & $1101[\mathrm{M}-\mathrm{H}]^{-}, 528[\mathrm{M}-\mathrm{COOH}-\mathrm{H}]^{2-}$ & 41 and 42 \\
\hline 18 & tellimagrandin II & $\begin{array}{l}\text { meadowsweet } \\
\text { inflorescence }\end{array}$ & 97.9 & $937[\mathrm{M}-\mathrm{H}]^{-}, 301[\text { ellagic acid }-\mathrm{H}]^{-}$ & 29 and 43 \\
\hline 19 & roshenin $\mathrm{C}$ & raspberry leaves & 93.8 & $783[\mathrm{M}-2 \mathrm{H}]^{2-}, 301[\text { ellagic acid }-\mathrm{H}]^{-}$ & 36 \\
\hline 20 & pedunculagin & raspberry leaves & 97.3 & $783[\mathrm{M}-\mathrm{H}]^{-}, 391[\mathrm{M}-2 \mathrm{H}]^{2-}$ & $\begin{array}{l}29,31 \\
\text { and } 44\end{array}$ \\
\hline 21 & carpinusin & wood cranesbill leaves & 99.7 & $951[\mathrm{M}-\mathrm{H}]^{-}, 933\left[\mathrm{M}-\mathrm{H}_{2} \mathrm{O}-\mathrm{H}\right]^{-}, 301[\text { ellagic acid }-\mathrm{H}]^{-}$ & 39 \\
\hline 22 & rugosin $\mathrm{E}$ & $\begin{array}{l}\text { meadowsweet } \\
\text { inflorescence }\end{array}$ & 99.8 & $860[\mathrm{M}-2 \mathrm{H}]^{2-}$ & 27 \\
\hline 23 & rugosin $\mathrm{D}$ & $\begin{array}{l}\text { meadowsweet } \\
\text { inflorescence }\end{array}$ & 99.4 & $936[\mathrm{M}-2 \mathrm{H}]^{2-}$ & 27 \\
\hline 24 & salicarinin A & $\begin{array}{l}\text { purple loosestrife } \\
\text { flowers and leaves }\end{array}$ & 97.8 & $933[\mathrm{M}-2 \mathrm{H}]^{2-}, 1867[\mathrm{M}-\mathrm{H}]^{-}$ & 45 \\
\hline 25 & strictinin & sea buckthorn leaves & 98.8 & $633[\mathrm{M}-\mathrm{H}]^{-}$ & $\begin{array}{l}29,31 \\
\text { and }\end{array}$ \\
\hline 26 & stachyurin & sea buckthorn leaves & 99.9 & $935[\mathrm{M}-\mathrm{H}]^{-}$ & $\begin{array}{l}31,35 \\
\text { and } 44\end{array}$ \\
\hline 27 & casuarinin & sea buckthorn leaves & 99.7 & $935[\mathrm{M}-\mathrm{H}]^{-}$ & $\begin{array}{l}31,35 \\
\text { and } 44\end{array}$ \\
\hline 28 & casuarictin & sea buckthorn leaves & 99.6 & $935[\mathrm{M}-\mathrm{H}]^{-}$ & $\begin{array}{l}31,35 \\
\text { and } 44\end{array}$ \\
\hline 29 & hippophaenin C & sea buckthorn leaves & 99.6 & $1103[\mathrm{M}-\mathrm{H}]^{-}$ & 46 \\
\hline 30 & hippophaenin B & sea buckthorn leaves & 98.2 & $1103[\mathrm{M}-\mathrm{H}]^{-}$ & 46 \\
\hline
\end{tabular}

ranged from 0.20 to 0.66 for $H$. contortus and from 0.06 to 0.56 for T. colubriformis (Figure 3). The direct mode of action of ETs was strong, and the kinetics of inhibition on larval exsheathment exhibited different patterns. Overall, three models of response to ETs based on LEIA were observed for the nematode species as illustrated by examples in Figure S3 in the Supporting Information. (i) The effect of ETs on LEIA showed a dose-dependent response, such as hippophaenin $\mathrm{B}$ (30) for $H$. contortus (Figure 3A). The incubation at $6.25 \mu \mathrm{M}$ solution had no effect on the larval exsheathment, and $100 \%$ of the larvae were exsheathed. Incubation at higher concentrations, $25 \mu \mathrm{M}, 0.1 \mathrm{mM}$, and $0.2 \mathrm{mM}$, inhibited the exsheathment, and only 85,38 , and $0 \%$ of the larvae were exsheathed, respectively. In general, as the concentration of these ETs increased, the inhibition on larval exsheathment increased. (ii) For some ETs, the inhibition was so strong that all concentrations above a certain value almost or completely inhibited exsheathment, such as tetrameric ET for H. contortus (Figure S3B in the Supporting Information). (iii) Some ETs had a weaker effect on the inhibition of larval exsheathment. For them, it was typical that only the $0.4 \mathrm{mM}$ concentration could inhibit the exsheathment, such as strictinin for $T$. colubriformis (Figure S3C in the Supporting Information). Strictinin was an example of a weak effect, where even with the 

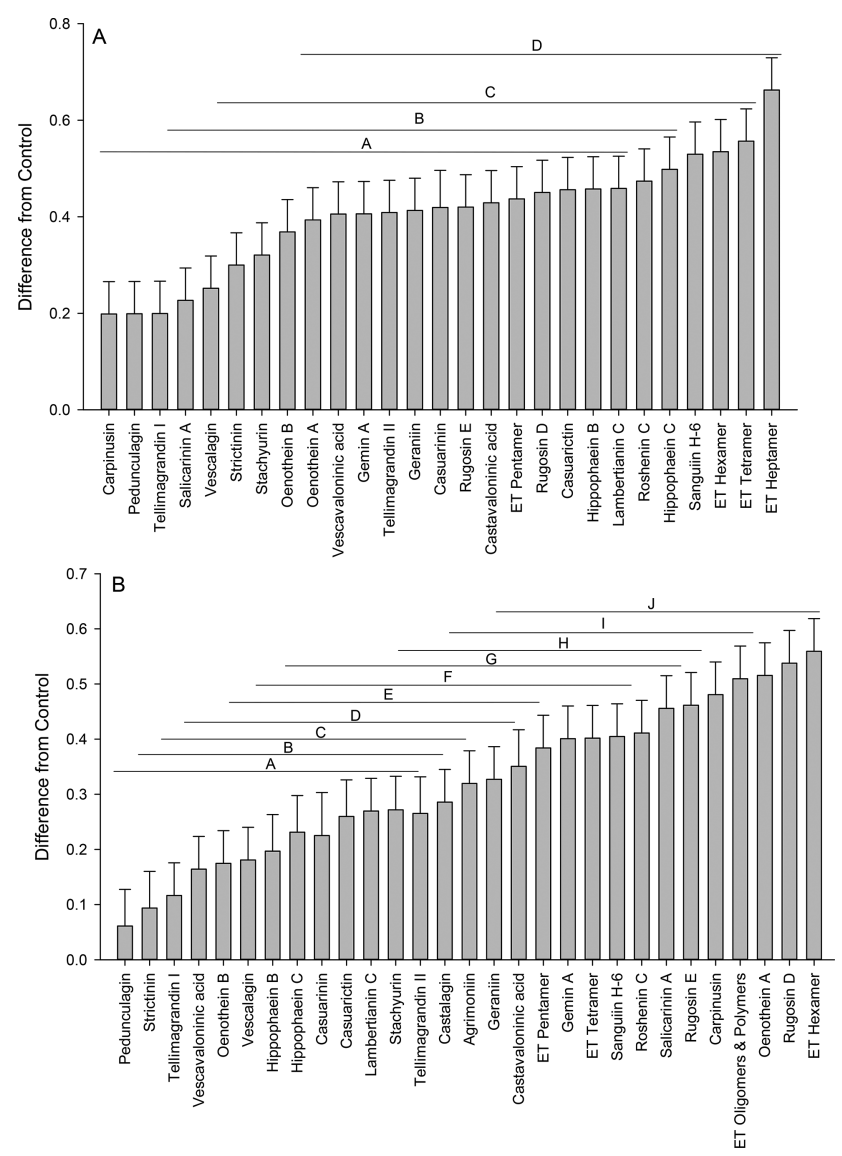

Figure 3. Effect of individual ellagitannins on larval exsheathment on the third-stage infective larvae of $H$. contortus (A) and T. colubriformis (B) evaluated by the average difference from the control, arranged in an ascending order. Ellagitannins that do not share a letter are significantly different at $\alpha=0.05$ after correction for the false discovery rate.

highest concentration of $0.4 \mathrm{mM}$, only $52 \%$ of larvae were exsheathed.

Effect of ETs on the Larval Exsheathment of $\boldsymbol{H}$. contortus. All ETs tested showed some anthelmintic effects by inhibiting the exsheathment of $H$. contortus (Figure 3A). The anthelmintic effect was evaluated by the difference in response from the control. The differences within ETs in their efficacy against $H$. contortus were evaluated by comparing least-squares mean values (Figure 4A). All parameters in the statistical model were highly significant: compound $\left(F_{26,347}=3.84, p<\right.$ $0.01)$, dose $\left(F_{1,347}=309.75, p<0.01\right)$, the compound by dose interaction $\left(F_{26,347}=2.27, p<0.01\right)$, and time $\left(F_{2,347}=41.27, p\right.$ $<0.01)$. Comparison of least-squares means results demonstrated that individual ETs varied in their efficacy against $H$. contortus. The most efficient ETs were the oligomeric ETs, such as ET tetramer (4), hexamer (6), and pentamer (5) in addition to hippophaenins (29 and 30), dimeric ETs sanguiin H-6 (14) and roshenin C (19), and trimeric ET lambertianin C (15) (Figure 4A). The least efficient ETs were the monomeric ETs carpinusin (21), pedunculagin (20), and tellimagrandin I (1), in addition to the dimeric ET salicarinin A (24) (Figure 3A).

Effect of ETs on the Larval Exsheathment of $T$. colubriformis. All ETs tested showed some anthelmintic effects by inhibiting the exsheathment of $T$. colubriformis (Figure 3B). As with $H$. contortus, the anthelmintic effect was
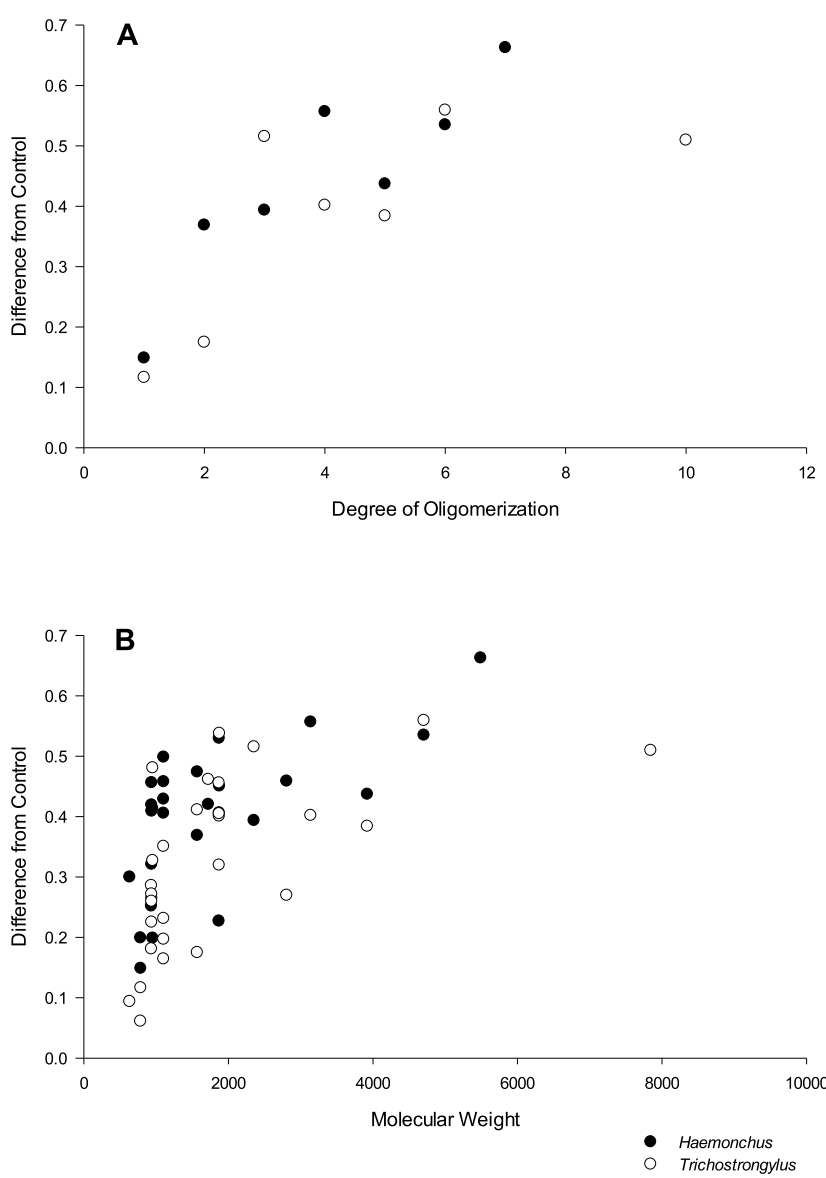

Figure 4. Effect of the degree of oligomerization (A) and molecular weight (B) on larval exsheathment on the third-stage infective larvae of $H$. contortus $(\bullet)$ and $T$. colubriformis $(O)$ evaluated by the average difference from the control.

evaluated by the difference in response from the control, and then, the differences within ETs in their efficacy against $T$. colubriformis were evaluated by comparing least-squares mean values (Figure 3B). All parameters in the statistical model were highly significant except for the compound by dose interaction: compound $\left(F_{28,349}=3.60, p<0.01\right)$, dose $\left(F_{1,349}=493.89, p<\right.$ $0.01)$, the compound by dose interaction $\left(F_{28,349}=1.45, p=\right.$ $0.07)$, and time $\left(F_{2,349}=9.41, p<0.01\right)$. Individual ETs varied in their efficacy against $T$. colubriformis. Again, the most efficient ETs were the oligomeric ETs, such as the ET trimer (3), the hexamer (6), and the mixture of larger ET oligomers (8), in addition to dimeric ETs rugosins D and E (23 and 22) and salicarinin A (24) (Figure 3B). Also, monomeric carpinusin (21) showed prominent anthelmintic activity. The least efficient ETs were monomeric pedunculagin (20), strictinin (25), and tellimagrandin I (1), in addition to vescavaloninic acid (16) (Figure 3B).

Effects of the Degree of Oligomerization and Molecular Weight of ET on Larval Exsheathment. In general, oligomeric ETs efficiently inhibited larval exsheathment on third-stage infective larvae of both nematode species (Figure 3). For example, with $H$. contortus, the monomeric tellimagrandin I ( 1 in Figure 1) had the weakest efficiency against the infective larvae in comparison to corresponding oligomeric ETs (dimeric ET 2 in Figures 2 and 3A). Dimeric oenothein B (2) was more efficient than monomeric tellimagrandin I (1) and trimeric oenothein A (3) was more 
efficient than dimeric oenothein B (2) (Figure 3A). The highest efficiency against infective larvae was found for the hexameric ET (7, Figure 3A). Overall, it was also noticed that the inhibition of exsheathment increased as the degree of oligomerization of ET increased (Figure 4A). A similar pattern was detected for all ETs and their molecular weights: the inhibition of exsheathment increased when the molecular weight of ETs increased (Figure 4B).

Effect of ETs on Larval Exsheathment between Two Nematode Species. The effects of individual ETs were different on the larval exsheathment on the third-stage infective larvae of two nematode species used as models in this study. In general, ETs were more efficient at inhibiting the exsheathment of $H$. contortus larvae than those of T. colubriformis (Figure 3; see also Figure S4 in the Supporting Information). However, the results varied greatly depending on the structure of ETs and the nematode species used. Some ETs, such as hexameric ET (7), were efficient inhibitors for both nematode species, whereas some ETs, such as carpinusin (21), were efficient only for one nematode species.

\section{DISCUSSION}

This study aims at further exploring the potential anthelmintic properties of ETs against gastrointestinal nematode species and the key stages of the life cycle of gastrointestinal nematodes. Previous results were obtained on eggs of $H$. contortus based on an in vitro egg hatch assay. ${ }^{24}$ The current study focused on the third-stage infective larvae by investigating the anthelmintic activities of 30 individual ETs against two main parasitic nematodes species $(H$. contortus and T. colubriformis) using the LEIA in vitro assay. All ETs showed in vitro anthelmintic activity against the two nematode species. This anthelmintic activity was affected by the concentration of the ET: as the dose increased, so did the response (Figure 3). In addition, ETs differed in how the activity changed with the dose, i.e., a dose $\times$ compound interaction was observed for both nematode species even though it was not significant for $T$. colubriformis $\left(F_{26,347}=2.27, p<0.01\right.$, for $H$. contortus; and $F_{28,349}=1.45, p=0.07$, for $T$. colubriformis). The anthelmintic activity was also affected by small changes in the ET structures. Based on averaged levels, the ETs differed from one another in their efficiency (Figure 3). The most important factors were the degree of oligomerization and the molecular weight of the ET (Figure 4). This finding was consistent with previous findings with hydrolyzable tannins - the molecular size affected the anthelmintic activity when the molecular weight was smaller than $940 \mathrm{Da}^{24}$ - and also with the other group of tannins: the polymer size of proanthocyanidin was associated with its anthelmintic activity against $H$. contortus when tested by LEIA. ${ }^{23}$ However, similar observations were not made for proanthocyanidins for T. colubriformis. ${ }^{23}$ Even though the degree of oligomerization was an important factor affecting the anthelmintic activity of the ETs, the same conclusion could not be clearly made for the nature of different oligomeric linkages. However, for $H$. contortus, the ET with an $m$-GOG linkage, i.e., gemin A (10 in Figure 2), had a weaker anthelmintic activity than the ETs with $m$-DOG linkages, i.e., rugosins E and D (22 and 23 in Figure 2), which again had weaker anthelmintic activities than the ETs with $m$-GOD linkages, i.e., sanguiin H-6 and lambertianin $\mathrm{C}$ (14 and $\mathbf{1 5}$ in Figure 2) (Figure 3A). Similar order was not detected for $T$. colubriformis, confirming previous results obtained with proanthocyanidins ${ }^{23}$ and thus suggesting differences depending on the nematode species.
These differences can be related to differences in the protein composition of the sheath of these two nematode species and possible changes in the interactions between tannins and proteins based on the direct hypothesis for the mode of action. $^{13}$

In addition to the degree of oligomerization and molecular weight of the ET, it was difficult to detect the actual structural features affecting the differences observed for individual ETs. The central glucose core seemed to play a role. As discussed above, the central glucose core of an ET monomer can be a ${ }^{4} \mathrm{C}_{1}$ D-glucopyranose, a ${ }^{1} \mathrm{C}_{4}$ D-glucopyranose, or an acyclic glucose. The structure of the central glucose core affected the anthelmintic activity slightly. In general, acyclic ETs (11, 12, 16, 17, 26, 27, 29, and 30 in Figure 1 and Table 1) seemed to be less efficient inhibitors than the cyclic ones $(1-10,13-15$, 18-25, and 28 in Figures 1, 2, and Table 1). The mean value of average differences from the control was $0.26 \pm 0.09$ for all acyclic ETs, whereas it was $0.35 \pm 0.15$ for all cyclic ETs with T. colubriformis. In comparison, it was $0.38 \pm 0.10$ for all acyclic ETs and $0.41 \pm 0.12$ for all cyclic ETs with $H$. contortus. However, distinct ETs with an acyclic glucose core showed anthelmintic activity of a different grade (Figure 4). For example, vescalagin was among the least efficient ones for both nematode species, whereas the hippophaenins B and C (30 and 29) were among the most efficient ones for $H$. contortus.

The C- 1 of the D-glucose core can have either an $\alpha$ or a $\beta$ configuration. For example, tellimagrandin I ( 1 in Figure 1) having the free $\mathrm{OH}$ group at the anomeric position has $\alpha$ and $\beta$ anomers, which cannot be isolated from each other, and they are present almost at a 1:1 ratio. These kinds of anomeric differences in ETs structures are small, but they may influence the chemical and biological properties of the compounds substantially. For example, vescalagin and castalagin have the same molecular weight of $934 \mathrm{Da}$ and the only difference in their structures is the orientation of the $\mathrm{OH}$ group at $\mathrm{C}-1$ of the glucose (11 and 12 in Figure 1). Previously, we observed with an egg hatch assay that the $\alpha$-orientation of the $\mathrm{OH}$ group of the ET increases its anthelmintic activity in comparison to the $\beta$-orientation of $\mathrm{OH}$ of the ET. ${ }^{24}$ Therefore, we assumed that we could observe a similar difference in the effect of these anomers on the larval exsheathment on the larvae of $H$. contortus and T. colubriformis. However, the results were not this straightforward. For $H$. contortus, the results seemed to be similar: $\beta$-anomers stachyurin and vescavaloninic acid (26 and 16 in Figure 1) showed weaker anthelmintic activities than the corresponding $\alpha$-anomers casuarinin and castavaloninic acid (27 and $\mathbf{1 7}$ in Figure 1)-when arranged in an ascending order of anthelmintic activity (Figure 3A). In comparison, vescavaloninic acid showed weaker anthelmintic activity than castavaloninic acid for T. colubriformis (Figure 3B). Nevertheless, similar observations were not made either for hippophaenins B and C (30 and 29, Figure 3) or for vescalagin and castalagin or stachyurin and casuarinin for $T$. colubriformis (Figure 3B). Most probably, this is due to the fact that the differences in the average differences from the control are so small and the standard deviations are so high that these acyclic ETs are not significantly different from each other (at $\alpha$ $=0.05$ after correction for the false discovery rate). A similar difficulty was observed when the effect of ${ }^{1} \mathrm{C}_{4}$ conformation of glucopyranose-based ETs was evaluated. No statistical difference was detected for geraniin (18 in Figure 1) and carpinusin (21 in Figure 1) against other ETs with a ${ }^{4} \mathrm{C}_{1}$ D-glucopyranose core (e.g., tellimagrandin I (1) in Figures 1 and 3). 
A lack of patterns was found with the other structural features of ETs. Although the results clearly showed that individual ETs varied in their efficacy against nematodes and the effect of compounds was statistically significant $\left(F_{26,347}=\right.$ 3.84, $p<0.01)$, any further conclusions could not be made about the effects of other structural features of individual ETs, such as the structural flexibility and the presence or number of free galloyl, NHTP, or DHHDP groups. It has been detected that structural flexibility affects the ability of ETs to bind to proteins, such as bovine serum albumin. ${ }^{25,51,52}$ This phenomenon can be significant if the inhibitive effects on larval exsheathment are a consequence of the propensity of tannins to form complexes with nematode proteins as previously discussed. ${ }^{7,13,53}$ Previous studies have also shown that free galloyl groups enhance the bioactivity of ETs. For example, when ETs are binding to proteins, the strong binding site is dependent on the presence of free galloyl groups. ${ }^{52}$

In this study, the effect of ETs was also dependent on the nematode species used; ETs were more efficient at inhibiting the exsheathment of $H$. contortus larvae than those of $T$. colubriformis. Previous in vitro results supported this observation as they had shown that tannins had different activities depending on the parasite species or the anatomical location. ${ }^{8,17,54}$ However, it was noticed that effects of different plant extracts were mostly similar to the third-stage larvae of $H$. contortus and T. colubriformis. ${ }^{14}$ The only difference was that heather extracts (Erica erigena) caused a significant delay in larval exsheathment for $H$. contortus but not for T. colubriformis. As discussed above, the inhibitive effects on larval exsheathment could be a consequence of the propensity of tannins to form complexes with nematode proteins. ${ }^{7,11,53}$ Tannins have the ability to form complexes with proteins, and there could be an interaction between ETs and the larval macromolecules, such as proteins and glycoproteins. The nature and strength of the ET-protein interaction are heavily dependent on the ET structure. $^{25,52}$ Therefore, it is logical that the anthelmintic effects are dependent on both the ET structures and the nematode species used.

The literature regarding the possible mode of action of tannins on the third-stage infective larvae is still limited. It has been reported that direct effects could be mediated through the interaction between proanthocyanidins and nematodes, thereby affecting the physiological functioning of gastrointestinal parasites. ' In general, proanthocyanidins from various forages have decreased the viability of the larval stages of several nematodes in sheep and goats. ${ }^{9}$ It has been hypothesized that tannins affect the capacity of infective larvae to establish in the mucosae of the host. ${ }^{53}$ However, the mode of action of tannins is still largely unidentified. Direct effect was detected as proanthocyanidins could interfere with the larval exsheathment, but these effects were not related to any changes in the mucosal cell response. ${ }^{53} \mathrm{~A}$ second hypothesis has been that tannins could act indirectly by improving the host response to parasites: tannins could protect proteins from ruminal degradation by binding them and later release them for digestion, thereby increasing the amino acid flow to the duodenum as demonstrated for proanthocyanidins. $7,9,11,53$ Previous in vitro results have shown that proanthocyanidins have different effects against different nematode species. ${ }^{23}$ Quijada et al. ${ }^{23}$ showed that the anthelmintic activity against $H$. contortus was associated with the monomeric prodelphinidin subunits and the degree of polymerization of proanthocyanidins, whereas, for T. colubriformis, the anthelmintic activity was correlated only with prodelphinidins. Their results suggested that proanthocyanidins have different modes of action against different parasite species. ${ }^{23}$ Therefore, it has been suggested that the composition of larval sheath proteins and the speciesspecific differences therein should be further studied to better understand the different modes of actions. ${ }^{23}$ Our previous results with the egg hatch assay suggested that hydrolyzable tannins do not penetrate the eggs and thereby do not directly disturb the development of the embryo. ${ }^{24}$ Instead, the hydrolyzable tannins could bind to the surface of the eggshell as shown by pentagalloyl glucose, presumably via tanninprotein interactions. After that, they may inhibit hatching by two different mechanisms: either by disturbing the proteins that initiate the actual hatching process or by disabling the larval penetration mechanistically. ${ }^{24}$ The current results for the effects of ETs on larval exsheathment were complicated as the only patterns detected were the effects of the degree of the oligomerization and the molecular weight of ETs. This hints that several different mechanisms can interact in the inhibition of the exsheathment. In the interaction governing the anthelmintic activity, it seems that both the structure of the ET and the proteins of the sheath are important. The interactions between ETs and proteins are both tannin- and protein-specific. $^{25,26}$

Previously, it has been hypothesized that a certain threshold of concentration needs to be reached before the proteintannin association is effective as no difference has been observed with the control and the lowest concentration of the sainfoin extract tested, i.e., $300 \mu \mathrm{g} / \mathrm{mL} .{ }^{53}$ We observed a similar pattern; it was typical that the lowest concentration used did not have an effect on the exsheathment (Figure S3 in the Supporting Information). In general, it was noticed that the inhibition on larval exsheathment increased as the concentration of ETs increased. This dose-dependent response has been documented previously with sainfoin proanthocyanidins tested against $H$. contortus. ${ }^{53,55}$ However, we used molar concentrations (from $6.25 \mu \mathrm{M}$ to $0.4 \mathrm{mM}$ ) to keep the number of molecules constant in the in vitro tests of different ETs. For example, the molecular weight of hippophaenin B (30) is 1104.8 Da, and its lowest concentration of $6.25 \mu \mathrm{M}$ corresponds to the mass concentration $6.9 \mu \mathrm{g} / \mathrm{mL}$, while for the tetrameric $\operatorname{ET}(4,3138.2 \mathrm{Da})$, the concentration is 19.6 $\mu \mathrm{g} / \mathrm{mL}$, and for the heptameric ET $(7,5491.8 \mathrm{Da})$, it is 34.3 $\mu \mathrm{g} / \mathrm{mL}$. In general, the threshold concentrations seem to be lower for ETs than for previously reported proanthocyanidins. $^{53}$ The mean effective concentrations that cause $50 \%$ exsheathment inhibition for proanthocyanidins are higher than $100 \mu \mathrm{g} / \mathrm{mL}$ : the concentration was $137 \mu \mathrm{g} / \mathrm{mL}$ for $H$. contortus and $233 \mu \mathrm{g} / \mathrm{mL}$ for $T$. colubriformis for proanthocyanidin fractions with a mean degree of polymerization of 2.8 from 18 different plant species and $108 \mu \mathrm{g} / \mathrm{mL}$ for $H$. contortus and 166 $\mu \mathrm{g} / \mathrm{mL}$ for $T$. colubriformis for proanthocyanidin fractions with a mean degree of polymerization of $8.4 .^{23}$

The concentrations used in the in vitro test need to be physiologically relevant and achievable in vivo in the different organs of the gastrointestinal tract after dietary consumption by the ruminants. The total content of soluble ETs varies greatly based on plant species and parts, but in general, high ET concentrations can be found in ET-rich plants. ${ }^{27}$ For example, L. salicaria (purple loosestrife) leaves and flowers and E. angustifolium (rosebay willowherb) flowers contain over 90 $\mathrm{mg} / \mathrm{g}$ total ETs in their crude extracts. If a sheep or goat eats $0.45 \mathrm{~kg}$ of dry ET-rich forage, such as willowherb with 
oligomeric $\mathrm{ETs}^{34}$ and $10 \%$ of this is ETs, then $45 \mathrm{~g}$ of ETs will be introduced to the rumen. If the volume of the rumen is approximately $5 \mathrm{~L},{ }^{56}$ then the ruminal ET concentration could in theory be $9 \mathrm{mg} / \mathrm{mL}$. Therefore, these micromolar concentrations should be physiologically relevant for an animal feeding on ET-rich forages.

In conclusion, the potential value of ETs to be exploited as an alternative solution to synthetic anthelmintics was investigated against the third-stage gastrointestinal nematodes and clarified for the very first time. ETs showed direct anthelmintic-like effects as they interfered and inhibited strongly the exsheathment of $H$. contortus and T. colubriformis larvae. The results obtained in this study emphasized the significance of knowing the ET structures found in plants. Some ETs were potent inhibitors for both nematode species, whereas some inhibited only one nematode species (Figure 3). These results emphasized the fact that the effects of tannins should not be dealt with tannin mixtures but individual compounds. The most important structural factors were the degree of oligomerization and the molecular weight of ETs. The effects of other structural features need to be further studied. By understanding the structure-activity relationships, we can clarify the factors causing the observed activities. Then, the ET-containing plants could be used appropriately in the context of sustainable farming practices. ETs and ETcontaining plants have a potential role as a component of an integrated approach in the control of nematode parasitism in livestock. The next insight could be to study the effects of these ETs on different life-cycle stages, such as adult nematodes, to comprehensively understand their role and mechanisms. Naturally, it must be taken into account that other plant polyphenols and components might have a synergistic or antagonistic effect on the activity of ETs. Therefore, the next step could also be to widen the current knowledge and test and use plant crude extracts and fractions rich in these specific ETs for their bioactivity. Resistance of synthetic anthelmintic drugs has become a major problem in veterinary medicine, and alternative treatments are essential. Therefore, these pioneering results form a good starting point for future studies on plantderived bioactive substances against gastrointestinal parasites. ETs may offer new, sustainable replacements for those anthelmintic drugs against which resistance is building up worldwide.

\section{ASSOCIATED CONTENT}

\section{(s) Supporting Information}

The Supporting Information is available free of charge at https://pubs.acs.org/doi/10.1021/acs.jafc.9b06774.

Structures of the ellagitannins characterized by NMR spectroscopy (Figures S1 and S2), different models and effects of ellagitannins on the larval exsheathment on the third-stage infective larvae (Figures S3 and S4), and NMR chemical shifts and coupling constants for the ellagitannins characterized (Tables S1-S5) (PDF)

\section{AUTHOR INFORMATION}

\section{Corresponding Author}

Maarit Karonen - Natural Chemistry Research Group, Department of Chemistry, University of Turku, FI-20014 Turku, Finland; o orcid.org/0000-0002-9964-6527; Phone: +358 29450 3179; Email: maarit.karonen@utu.fi; Fax: +358 294505040

\section{Authors}

Jeffrey R. Ahern - Natural Chemistry Research Group, Department of Chemistry, University of Turku, FI-20014 Turku, Finland

Lucie Legroux - UMR 1225 IHAP, INRAE/ENVT, 31076 Toulouse, France

Jussi Suvanto - Natural Chemistry Research Group, Department of Chemistry, University of Turku, FI-20014 Turku, Finland; 이이이.org/0000-0002-2138-0984

Marica T. Engström - Natural Chemistry Research Group, Department of Chemistry, University of Turku, FI-20014 Turku, Finland; 이이.org/0000-0003-4123-6039

Jari Sinkkonen - Natural Chemistry Research Group, Department of Chemistry, University of Turku, FI-20014 Turku, Finland

Juha-Pekka Salminen - Natural Chemistry Research Group, Department of Chemistry, University of Turku, FI-20014 Turku, Finland; 이이. orcid.org/0000-0002-2912-7094

Hervé Hoste - UMR 1225 IHAP, INRAE/ENVT, 31076 Toulouse, France

Complete contact information is available at:

https://pubs.acs.org/10.1021/acs.jafc.9b06774

\section{Funding}

This research was funded by the Academy of Finland (grant numbers 251388 and 310549 to M.K.). Authors J.-P.S. and H.H. received funding through a Marie Curie Initial Training Network from the European Union ("LegumePlus", PITNGA-2011-289377). Analyses and characterization of ETs on the UHPLC-ESI-MS/MS system were made possible by a Strategic Research Grant of University of Turku (Ecological Interactions).

Notes

The authors declare no competing financial interest.

\section{ACKNOWLEDGMENTS}

Anu Tuominen, Mika Karonen, and other gatherers are thanked for their help in the collection of plant materials. Milla Leppä, Jorma Kim, Elina Puljula, Hanna-Mari Salmia, Atte Tuominen, and Valtteri Virtanen are acknowledged for their help in the isolation, purification, and characterization of ETs and Jessica Quijada for her help in larval exsheathment inhibition assays. Juuso Laitila is thanked for his kind help in the editing of Figures 3 and S4.

\section{ABBREVIATIONS}

DHHDP, dehydrohexahydroxydiphenoyl; $m$-DOG, valoneoyl group; ESI, electrospray ionization; ET, ellagitannin; HHDP, hexahydroxydiphenoyl; HPLC-DAD, high-performance liquid chromatography-diode array detection; L3, third-stage infective larvae; LEIA, larval exsheathment inhibition assay; $m$ GOD, sanguisorboyl group; $m$-GOG, meta-dehydrodigalloyl group; NHTP, nonahydroxytriphenoyl; PBS, phosphatebuffered solution; UPLC-DAD-MS, ultraperformance liquid chromatography-diode array detection-mass spectrometry

\section{REFERENCES}

(1) Waller, P. J. From Discovery to Development: Current Industry Perspectives for the Development of Novel Methods of Helminth Control in Livestock. Vet. Parasitol. 2006, 139, 1-14.

(2) Charlier, J.; Velde, F. V.; van der Voort, M.; Meensel, J. V.; Lauwers, L.; Cauberghe, V.; Vercruysse, J.; Claerebout, E. 
ECONOHEALTH: Placing Helminth Infections of Livestock in an Economic and Social Context. Vet. Parasitol. 2015, 212, 62-67.

(3) Wolstenholme, A. J.; Fairweather, I.; Prichard, R.; Von SamsonHimmelstjerna, G.; Sangster, N. C. Drug Resistance in Veterinary Helminths. Trends Parasitol. 2004, 20, 469-476.

(4) Rose, H.; Rinaldi, L.; Bosco, A.; Mavrot, F.; de Waal, T.; Skuce, P.; Charlier, J.; Torgerson, P. R.; Hertzberg, H.; Hendrickx, G.; et al. Widespread Anthelmintic Resistance in European Farmed Ruminants: A Systematic Review. Vet. Rec. 2015, 176, 546.

(5) Kaplan, R. M.; Vidyashankar, A. N. An Inconvenient Truth: Global Worming and Anthelmintic Resistance. Vet. Parasitol. 2012, 186, 70-78.

(6) Kotze, A. C.; Prichard, R. K. Anthelmintic Resistance in Haemonchus contortus: History, Mechanisms and Diagnosis. Adv. Parasitol. 2016, 93, 397-428.

(7) Kahn, L. P.; Diaz-Hernandez, A. Tannins with Anthelmintic Properties. In Tannins in Livestock and Human Nutrition, ACIAR Proceedings No. 92; Brooker, J. D., Ed.; ACIAR: Adelaide, 1999; pp 140-149.

(8) Athanasiadou, S.; Kyriazakis, I.; Jackson, F.; Coop, R. L. Direct Anthelmintic Effects of Condensed Tannins towards Different Gastrointestinal Nematodes of Sheep: In Vitro and in Vivo Studies. Vet. Parasitol. 2001, 99, 205-219.

(9) Min, B. R.; Hart, S. P. Tannins for Suppression of Internal Parasites. J. Anim. Sci. 2002, 81, 102-109.

(10) Ketzis, J. K.; Vercruysse, J.; Stromberg, B. E.; Larsen, M.; Athanasiadou, S.; Houdijk, J. G. M. Evaluation of Efficacy Expectations for Novel and Non-Chemical Helminth Control Strategies in Ruminants. Vet. Parasitol. 2006, 139, 321-335.

(11) Hoste, H.; Jackson, F.; Athanasiadou, S.; Thamsborg, S. M.; Hoskin, S. O. The Effects of Tannin-Rich Plants on Parasitic Nematodes in Ruminants. Trends Parasitol. 2006, 22, 253-261.

(12) Hoste, H.; Torres-Acosta, J. F. J.; Sandoval-Castro, C. A.; Mueller-Harvey, I.; Sotiraki, S.; Louvandini, H.; Thamsborg, S. M.; Terrill, T. H. Tannin Containing Legumes as a Model for Nutraceuticals against Digestive Parasites in Livestock. Vet. Parasitol. 2015, 212, 5-17.

(13) Hoste, H.; Martinez-Ortiz-De-montellano, C.; Manolaraki, F.; Brunet, S.; Ojeda-Robertos, N.; Fourquaux, I.; Torres-Acosta, J. F. J.; Sandoval-Castro, C. A. Direct and Indirect Effects of Bioactive Tannin-Rich Tropical and Temperate Legumes against Nematode Infections. Vet. Parasitol. 2012, 186, 18-27.

(14) Bahuaud, D.; De Montellano, C. M.-O.; Chauveau, S.; Prevot, F.; Torres-Acosta, F.; Fouraste, I.; Hoste, H. Effects of Four Tanniferous Plant Extracts on the in Vitro Exsheathment of ThirdStage Larvae of Parasitic Nematodes. Parasitology 2006, 132, 545554.

(15) Salminen, J.-P.; Karonen, M. Chemical Ecology of Tannins and Other Phenolics: We Need a Change in Approach. Funct. Ecol. 2011, $25,325-338$.

(16) Quideau, S.; Deffieux, D.; Douat-Casassus, C.; Pouységu, L. Plant Polyphenols: Chemical Properties, Biological Activities, and Synthesis. Angew. Chemi., Int. Ed. 2011, 50, 586-621.

(17) Paolini, V.; Frayssines, A.; De La Farge, F.; Dorchies, P.; Hoste, H. Effects of Condensed Tannins on Established Populations and on Incoming Larvae of Trichostrongylus colubriformis and Teladorsagia circumcincta in Goats. Vet. Res. 2003, 34, 331-339.

(18) Paolini, V.; Fouraste, I.; Hoste, H. In Vitro Effects of Three Woody Plant and Sainfoin Extracts on 3rd-Stage Larvae and Adult Worms of Three Gastrointestinal Nematodes. Parasitology 2004, 129, 69-77.

(19) Butter, N. L.; Dawson, J. M.; Wakelin, D.; Buttery, P. J. Effect of Dietary Condensed Tannins on Gastrointestinal Nematodes. J. Agric. Sci. 2001, 137, 461-469.

(20) Novobilský, A.; Stringano, E.; Hayot Carbonero, C.; Smith, L. M. J.; Enemark, H. L.; Mueller-Harvey, I.; Thamsborg, S. M. In Vitro Effects of Extracts and Purified Tannins of Sainfoin (Onobrychis viciifolia) against Two Cattle Nematodes. Vet. Parasitol. 2013, 196, $532-537$.
(21) Williams, A. R.; Fryganas, C.; Ramsay, A.; Mueller-Harvey, I.; Thamsborg, S. M. Direct Anthelmintic Effects of Condensed Tannins from Diverse Plant Sources against Ascaris suum. PLoS One 2014, 9, No. e97053.

(22) Williams, A. R.; Ropiak, H. M.; Fryganas, C.; Desrues, O.; Mueller-Harvey, I.; Thamsborg, S. M. Assessment of the Anthelmintic Activity of Medicinal Plant Extracts and Purified Condensed Tannins against Free-Living and Parasitic Stages of Oesophagostomum dentatum. Parasites Vectors 2014, 7, 518.

(23) Quijada, J.; Fryganas, C.; Ropiak, H. M.; Ramsay, A.; MuellerHarvey, I.; Hoste, H. Anthelmintic Activities against Haemonchus contortus or Trichostrongylus colubriformis from Small Ruminants Are Influenced by Structural Features of Condensed Tannins. J. Agric. Food Chem. 2015, 63, 6346-6354.

(24) Engström, M. T.; Karonen, M.; Ahern, J. R.; Baert, N.; Payré, B.; Hoste, H.; Salminen, J.-P. Chemical Structures of Plant Hydrolyzable Tannins Reveal Their in Vitro Activity against Egg Hatching and Motility of Haemonchus contortus Nematodes. J. Agric. Food Chem. 2016, 64, 840-851.

(25) Karonen, M.; Oraviita, M.; Mueller-Harvey, I.; Salminen, J.-P.; Green, R. J. Binding of an Oligomeric Ellagitannin Series to Bovine Serum Albumin (BSA): Analysis by Isothermal Titration Calorimetry (ITC). J. Agric. Food Chem. 2015, 63, 10647-10654.

(26) Karonen, M.; Oraviita, M.; Mueller-Harvey, I.; Salminen, J.-P.; Green, R. J. Ellagitannins with Glucopyranose Cores Have Higher Affinities to Proteins than Acyclic Ellagitannins by Isothermal Titration Calorimetry. J. Agric. Food Chem. 2019, 67, 12730-12740.

(27) Moilanen, J.; Koskinen, P.; Salminen, J.-P. Distribution and Content of Ellagitannins in Finnish Plant Species. Phytochemistry 2015, 116, 188-197.

(28) Salminen, J.-P.; Ossipov, V.; Loponen, J.; Haukioja, E.; Pihlaja, K. Characterisation of Hydrolysable Tannins from Leaves of Betula pubescens by High-Performance Liquid Chromatography-Mass Spectrometry. J. Chromatogr. A 1999, 864, 283-291.

(29) Salminen, J.-P.; Ossipov, V.; Haukioja, E.; Pihlaja, K. Seasonal Variation in the Content of Hydrolysable Tannins in Leaves of Betula pubescens. Phytochemistry 2001, 57, 15-22.

(30) Salminen, J.-P.; Karonen, M.; Sinkkonen, J. Chemical Ecology of Tannins: Recent Developments in Tannin Chemistry Reveal New Structures and Structure-Activity Patterns. Chem. - Eur. J. 2011, 17, 2806-2816.

(31) Moilanen, J.; Salminen, J.-P. Ecologically Neglected Tannins and Their Biologically Relevant Activity: Chemical Structures of Plant Ellagitannins Reveal Their in Vitro Oxidative Activity at High pH. Chemoecology 2008, 18, 73-83.

(32) Karonen, M.; Parker, J.; Agrawal, A.; Salminen, J.-P. First Evidence of Hexameric and Heptameric Ellagitannins in Plants Detected by Liquid Chromatography/Electrospray Ionisation Mass Spectrometry. Rapid Commun. Mass Spectrom. 2010, 24, 3151-3156.

(33) Salminen, J.-P.; Karonen, M. Chemical Ecology of Tannins and Other Phenolics: We Need a Change in Approach. Funct. Ecol. 2011, $25,325-338$.

(34) Baert, N.; Karonen, M.; Salminen, J.-P. Isolation, Characterisation and Quantification of the Main Oligomeric Macrocyclic Ellagitannins in Epilobium angustifolium by Ultra-High Performance Chromatography with Diode Array Detection and Electrospray Tandem Mass Spectrometry. J. Chromatogr. A 2015, 1419, 26-36.

(35) Moilanen, J.; Sinkkonen, J.; Salminen, J.-P. Characterization of Bioactive Plant Ellagitannins by Chromatographic, Spectroscopic and Mass Spectrometric Methods. Chemoecology 2013, 23, 165-179.

(36) Yoshida, T.; Feng, W.-S.; Okuda, T. Tannins and Related Polyphenols of Rosaceous Medicinal Plants. XII. Roshenins A-E, Dimeric Hydrolyzable Tannins from Rosa henryi BOUL. Chem. Pharm. Bull. 1992, 40, 1997-2001.

(37) Rauha, J.-P.; Wolfender, J.-L.; Salminen, J.-P.; Pihlaja, K.; Hostettmann, K.; Vuorela, H. Characterization of the Polyphenolic Composition of Purple Loosestrife (Lythrum salicaria). Z. Naturforsch., C: J. Biosci. 2001, 56, 13-20. 
(38) Salminen, J.-P.; Roslin, T.; Karonen, M.; Sinkkonen, J.; Pihlaja, K.; Pulkkinen, P. Seasonal Variation in the Content of Hydrolyzable Tannins, Flavonoid Glycosides, and Proanthocyanidins in Oak Leaves. J. Chem. Ecol. 2004, 30, 1693-1711.

(39) Tuominen, A.; Toivonen, E.; Mutikainen, P.; Salminen, J.-P. Defensive Strategies in Geranium sylvaticum. Part 1: Organ-Specific Distribution of Water-Soluble Tannins, Flavonoids and Phenolic Acids. Phytochemistry 2013, 95, 394-407.

(40) Mullen, W.; Yokota, T.; Lean, M. E. J.; Crozier, A. Analysis of Ellagitannins and Conjugates of Ellagic Acid and Quercetin in Raspberry Fruits by LC-MSn. Phytochemistry 2003, 64, 617-624.

(41) Yarnes, C. T.; Boecklen, W. J.; Tuominen, K.; Salminen, J.-P. Defining Phytochemical Phenotypes: Size and Shape Analysis of Phenolic Compounds in Oaks (Fagaceae, Quercus) of the Chihuahuan Desert. Can. J. Bot. 2006, 84, 1233-1248.

(42) Yarnes, C. T.; Boecklen, W. J.; Salminen, J.-P. No Simple Sum: Seasonal Variation in Tannin Phenotypes and Leaf-Miners in Hybrid Oaks. Chemoecology 2008, 18, 39-51.

(43) Okuda, T.; Yoshida, T.; Hatano, T.; Yazaki, K.; Ashida, M. Ellagitannins of the Casuarinaceae, Stachyuraceae and Myrtaceae. Phytochemistry 1980, 21, 2871-2874.

(44) Yoshida, T.; Tanaka, K.; Chen, X.; Okuda, T. Tannins from Hippophae rhamnoides. Phytochemistry 1991, 30, 663-666.

(45) Piwowarski, J. P.; Kiss, A. K. C-Glucosidic Ellagitannins from Lythri Herba (European pharmacopoeia): Chromatographic Profile and Structure Determination. Phytochem. Anal. 2013, 24, 336-348.

(46) Suvanto, J.; Tähtinen, P.; Valkamaa, S.; Engström, M. T.; Karonen, M.; Salminen, J.-P. Variability in Foliar Ellagitannins of Hippophäe rhamnoides L. and Identification of a New Ellagitannin, Hippophaenin C. J. Agric. Food Chem. 2018, 66, 613-620.

(47) Matsuo, Y.; Wakamatsu, H.; Omar, M.; Tanaka, T. Reinvestigation of the Stereochemistry of the C-Glycosidic Ellagitannins, Vescalagin and Castalagin. Org. Lett. 2015, 17, 46-49.

(48) Okuda, T.; Yoshida, T.; Hatano, T.; Iwasaki, M.; Kubo, M.; Orime, T.; Yoshizaki, M.; Naruhashi, N. Hydrolysable Tannins as Chemotaxonomic Markers in the Rosaceae. Phytochemistry 1992, 31, 3091-3096.

(49) Yoshida, T.; Maruyama, Y.; Memon, M. U.; Shingu, T.; Okuda, T. Gemins D, E and F, Ellagitannins from Geum japonicum. Phytochemistry 1985, 24, 1041-1046.

(50) Benjamini, Y.; Hochberg, Y. Controlling the False Discovery Rate: A Practical and Powerful Approach to Multiple Testing. J. R. Stat. Soc. 1995, 57, 289-300.

(51) Deaville, E. R.; Green, R. J.; Mueller-Harvey, I.; Willoughby, I.; Frazier, R. A. Hydrolyzable Tannin Structures Influence Relative Globular and Random Coil Protein Binding Strengths. J. Agric. Food Chem. 2007, 55, 4554-4561.

(52) Dobreva, M. A.; Green, R. J.; Mueller-Harvey, I.; Salminen, J.P.; Howlin, B. J.; Frazier, R. A. Size and Molecular Flexibility Affect the Binding of Ellagitannins to Bovine Serum Albumin. J. Agric. Food Chem. 2014, 62, 9186-9194.

(53) Brunet, S.; Jackson, F.; Hoste, H. Effects of Sainfoin ( Onobrychis viciifolia) Extract and Monomers of Condensed Tannins on the Association of Abomasal Nematode Larvae with Fundic Explants. Int. J. Parasitol. 2008, 38, 783-790.

(54) Paolini, V.; Prevot, F.; Dorchies, P.; Hoste, H. Lack of Effects of Quebracho and Sainfoin Hay on Incoming Third-Stage Larvae of Haemonchus contortus in Goats. Vet. J. 2005, 170, 260-263.

(55) Brunet, S.; Aufrere, J.; El Babili, F.; Fouraste, I.; Hoste, H. The Kinetics of Exsheathment of Infective Nematode Larvae Is Disturbed in the Presence of a Tannin-Rich Plant Extract (Sainfoin) Both in Vitro and in Vivo. Parasitology 2007, 134, 1253-1262.

(56) Purser, D.; Moir, R. Rumen Volume as a Factor Involved in Individual Sheep Differences. J. Anim. Sci. 1966, 25, 509-515. 